Original Contribution

\title{
Functional muscle impairment in facioscapulohumeral muscular dystrophy is correlated with oxidative stress and mitochondrial dysfunction
}

\author{
Ahmed Turki ${ }^{a}$, Maurice Hayot ${ }^{\mathrm{a}, \mathrm{b}}$, Gilles Carnac ${ }^{\mathrm{a}}$, Fabien Pillard ${ }^{\mathrm{c}}$, Emilie Passerieux ${ }^{\mathrm{a}}$, \\ Sébastien Bommart ${ }^{\mathrm{a}, \mathrm{b}}$, Eric Raynaud de Mauverger ${ }^{\mathrm{a}, \mathrm{b}}$, Gérald Hugon ${ }^{\mathrm{a}}$, Joel Pincemail ${ }^{\mathrm{d}}$, \\ Sylvia Pietri ${ }^{\mathrm{e}}$, Karen Lambert ${ }^{\mathrm{a}}$, Alexandra Belayew ${ }^{\mathrm{f}}$, Yegor Vassetzky ${ }^{\mathrm{g}}$, Raul Juntas Morales ${ }^{\mathrm{h}}$, \\ Jacques Mercier ${ }^{\text {a,b }}$, Dalila Laoudj-Chenivesse ${ }^{a, *}$ \\ a Université Montpellier 1 et Université Montpellier 2, INSERM, U1046, Montpellier, F-34000, France \\ ${ }^{\mathrm{b}}$ CHRU, Hôpital A. de Villeneuve, Montpellier, F-34000, France \\ ${ }^{\mathrm{c}}$ Hôpital Larrey, Service d'Exploration de la Fonction Respiratoire et de Médecine du Sport, F-31000 Toulouse, France \\ ${ }^{\mathrm{d}} \mathrm{CHU}$, Bld de l'Hôpital Service du CREDEC, Tour de Pathologie $5^{\text {ème }}$ étage, Sart Tilman 4000 Liège, Belgium \\ e SMB-LCP-UMR 6264 CNRS-Universités d'Aix-Marseille, Centre Saint-Jérôme, Marseille, France \\ ${ }^{\mathrm{f}}$ Service de Biologie Moléculaire, Université de Mons; 7000 Mons, Belgium \\ ${ }^{\mathrm{g}}$ UMR 8126, CNRS - Université Paris-Sud 11, Institut de Cancérologie Gustave-Roussy, F-94804 Villejuif, France

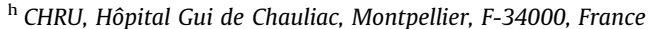

\section{A R T I C L E I N F O}

\section{Article history:}

Received 9 March 2012

Received in revised form

5 June 2012

Accepted 28 June 2012

Available online 11 July 2012

Keywords:

Facioscapulohumeral muscular

dystrophy (FSHD)

4-Hydroxy-2-nonenal

Thiobarbituric acid-reactive substances

Lipofuscin

Oxidative stress

Protein oxidation

Radical oxygen species

Mitochondria dysfunction

Antioxidants

\begin{abstract}
A B S T R A C T
Facioscapulohumeral muscular dystrophy (FSHD), the most frequent muscular dystrophy, is an autosomal dominant disease. In most individuals with FSHD, symptoms are restricted to muscles of the face, arms, legs, and trunk. FSHD is genetically linked to contractions of the D4Z4 repeat array causing activation of several genes. One of these maps in the repeat itself and expresses the DUX4 (the double homeobox 4) transcription factor causing a gene deregulation cascade. In addition, analyses of the RNA or protein expression profiles in muscle have indicated deregulations in the oxidative stress response. Since oxidative stress affects peripheral muscle function, we investigated mitochondrial function and oxidative stress in skeletal muscle biopsies and blood samples from patients with FSHD and age-matched healthy controls, and evaluated their association with physical performances. We show that specifically, oxidative stress (lipid peroxidation and protein carbonylation), oxidative damage (lipofuscin accumulation), and antioxidant enzymes (catalase, copper-zinc-dependent superoxide dismutase, and glutathione reductase) were higher in FSHD than in control muscles. FSHD muscles also presented abnormal mitochondrial function (decreased cytochrome $c$ oxidase activity and reduced ATP synthesis). In addition, the ratio between reduced (GSH) and oxidized glutathione (GSSG) was strongly decreased in all FSHD blood samples as a consequence of GSSG accumulation. Patients with FSHD also had reduced systemic antioxidative response molecules, such as low levels of zinc (a SOD cofactor), selenium (a GPx cofactor involved in the elimination of lipid peroxides), and vitamin C. Half of them had a low ratio of gamma/alpha tocopherol and higher ferritin concentrations. Both systemic oxidative stress and mitochondrial dysfunction were correlated with functional muscle impairment. Mitochondrial ATP production was significantly correlated with both quadriceps endurance $\left(T_{\text {LimQ }}\right)$ and maximal voluntary contraction $\left(\mathrm{MVC}_{\mathrm{Q}}\right)$ values $(\mathrm{rho}=0.79, P=0.003$; rho $=0.62$, $P=0.05$, respectively). The plasma concentration of oxidized glutathione was negatively correlated with the $T_{\mathrm{LimQ}}, \mathrm{MVC}_{\mathrm{Q}}$ values, and the 2 -min walk distance $(\mathrm{MWT})$ values (rho $=-0.60, P=0.03$; rho $=-0.56, P=0.04$; rho $=-0.93, P<0.0001$, respectively). Our data characterized oxidative stress in patients with FSHD and demonstrated a correlation with their peripheral skeletal muscle dysfunction. They suggest that antioxidants that might modulate or delay oxidative insult may be useful in maintaining FSHD muscle functions.
\end{abstract}

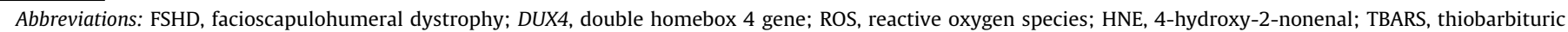

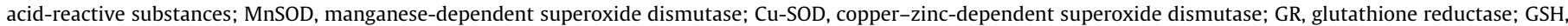
reduced glutathione; GSSG, oxidized glutathione; MVC, maximal voluntary contraction; $T_{\text {Lim }}$, endurance limit time; 2 -MWT, 2 minute walking test

* Correspondence to: INSERM, U1046, Bâtiment Crastes de Paulet, 371 avenue du Doyen Giraud, 34295 Montpellier, France. Fax: +33 0467415221.

E-mail address: dalila.laoudj-chenivesse@inserm.fr (D. Laoudj-Chenivesse).
} 


\section{Introduction}

Facioscapulohumeral muscular dystrophy (FSHD) is an autosomal dominant muscle disease characterized by progressive weakness and atrophy of facial, shoulder girdle, and upper arm muscles. Magnetic resonance imaging also revealed widespread involvement of leg muscles, particularly of the tibialis anterior and medial gastronemius [1], that may result in walking difficulties. Approximately $10 \%$ of all patients and $20 \%$ of those who are older than 50 years will eventually become wheelchair dependent for outdoor activities [2,3]. Less frequent clinical manifestations including respiratory [4] and cardiac conduction [5] defects may occur in patients severely affected with FSHD. Finally, many patients complain of pain and fatigue, which are likely to reduce the levels of daily activity.

FSHD is genetically linked to deletions in chromosome $4 \mathrm{q} 35$ [6,7] within an array of D4Z4 repeated elements with each composing the double homeobox 4 (DUX4) gene [8,9]. Several analyses of gene expression in FSHD muscle have produced partially overlapping and sometimes contradictory results [10-15]. D4Z4 contractions are proposed to cause epigenetic changes, which ultimately increase expression of genes with myopathic potential [6,16-19], particularly ANT1, FRG1, DUX4c, FRG2, and DUX4 [9,20-24]. Expression of the DUX4 protein in muscles is now considered the major contributor to the molecular pathogenesis of FSHD $[23,25,26]$. DUX4 is a transcription factor that initiates a large gene deregulation cascade. Its forced expression in muscle cells is toxic and induces typical FSHD molecular features, such as muscle atrophy markers and TP53, diminished myogenic differentiation capacity, sensitivity to oxidative stress, and genes expressed in germline and early stem cells where DUX4 is normally expressed [22,24,25,27,28].

In addition, analysis of the RNA or protein expression profiles in peripheral muscles of patients with FSHD compared to healthy controls revealed that many genes differentially expressed in affected and nonaffected FSHD muscles are specifically involved in oxidative stress responses [14,29-33]. Indeed, these genes are not deregulated in other muscular dystrophies such as DMD and LGMD2B and the activation of some of them (ANT1 encoding a mitochondrial protein; DUX4 encoding a transcription factor) are linked to the chromatin opening in $4 \mathrm{q} 35$, suggesting that aberrations in this pathway could be the primary events rather than consequences of the muscle pathology [29-31]. The FSHD specificity of this defect is also underscored by the susceptibility of primary myoblasts to oxidative agents and alteration in gene expression and protein synthesis involved in oxidative stress responses [14,32].

Since oxidative stress affects peripheral muscle function, we investigated mitochondrial function and oxidative stress in blood samples and skeletal muscle biopsies from patients with FSHD and healthy controls. We then evaluated their association with physical performance.

\section{Materials and methods}

\section{Patients}

Fifteen patients with FSHD (9 males and 6 females) and 9 healthy subjects (6 males and 3 females) matched for age (FSHD, 38.9 years \pm 10.8 ; controls, 35.7 years \pm 10.2 ) and physical activity level were sequentially recruited over 2 years in the Department of Clinical Physiology, University Hospital, Montpellier (France). Patients with FSHD were not wheelchair bound and diagnosis was based on clinical examination, number of D4Z4 units ( 4 to 9 by DNA analysis), and positive family history for FSHD. The Brooke and Vignos functional scales are used to grade arm and leg function, respectively [34]. Twelve of 15 patients were ranked between 1 and 2 for arms and in rank 1 for legs according to that scale. The other three patients were more affected and ranked between 4 and 5 for arms and for legs. Controls and patients were sedentary (Voorrips questionnaire's score $<9.4$ ) [35] and did not participate in any kind of physical training or rehabilitation. All were nonsmokers, had no comorbidity (such as cardiac or pulmonary disease, diabetes or human immunodeficiency virus), and were not taking any drug, including vitamins and/or antioxidants. The protocol was approved by the local review board (Ethics Committee of the CHU Saint Eloi, Montpellier, France; reference number 0505 03). Participants received extensive information about the study before providing their written informed consent. All functional and clinical evaluations and muscle biopsies were performed in the Department of Clinical Physiology, University Hospital, Montpellier (France).

\section{Clinical and functional evaluation}

Spirometry was performed using a plethysmograph (Spirometer Vmax, Sensormedics, US). Maximal inspiratory $\left(P_{\mathrm{Imax}}\right)$ and expiratory $\left(P_{\text {Emax }}\right)$ pressures were also measured [36].

For maximal voluntary contraction and endurance of quadriceps and deltoid muscles, each leg's quadriceps maximal voluntary contraction $\left(\mathrm{MVC}_{\mathrm{Q}}\right)$ and endurance $\left(T_{\text {Limo }}\right)$ were assessed on an adapted exercise bench (Kettler, Germany) in seated position with knees and hips flexed at $90^{\circ}$, as previously reported [37-40]. $M V C_{Q}$ was recorded through a strain gauge linked to a computer interface (Biopac, Acknowledge, France). Three to five maximal trials were performed to obtain at least two values with less than $10 \%$ variability. The best value was taken as the $\mathrm{MVC}_{\mathrm{Q}}$.

To assess quadriceps endurance ( $\left.T_{\text {LimQ }}\right)$, subjects had to maximally extend each knee against a weight that corresponded to $30 \%$ of the $M V C_{Q}$ at a pace of 10 movements per minute, imposed by an audio signal, until exhaustion. The duration of the endurance test (in seconds) was called quadriceps endurance limit time $\left(T_{\text {LimQ }}\right)$. The leg with the highest $T_{\text {Lime }}$ was considered the "reference leg" and chosen for the biopsy.

The deltoid maximal isometric voluntary contraction $\left(\mathrm{MVC}_{\mathrm{D}}\right)$ was bilaterally assessed using the same signal recorder as quadriceps measurements with the strain gauge fixed in order to maintain shoulder and arm at $90^{\circ}$. The subjects were in the sitting position and were asked to develop a maximal contraction by elevating the arm against the fixed strain gauge during a maximal effort with verbal encouragement. Three to 5 trials were performed and the best value of 3 reproducible maneuvers (within $10 \%$ ) was considered as the $M V C_{D}$. Endurance was also bilaterally assessed against $30 \%$ of the recorded $\mathrm{MVC}_{\mathrm{D}}$. Subjects with a charge connected to a handle were asked to maintain the upper arm at $90^{\circ}$. Verbal encouragement was provided along the effort until exhaustion; i.e., the subject could not maintain his/her arm at the desired position and therefore stopped the contraction. The duration of the endurance test was called endurance limit time of the deltoid $\left(T_{\text {LimD }}\right)$.

The 2-minute walking test (2-MWT) was carried out as previously described $[41,42]$. Subjects were asked to walk back and forth around two cones placed in an indoor, straight, 30-m corridor for $2 \mathrm{~min}$. Two tests separated by $60 \mathrm{~min}$ were performed at a maximum walking pace with the goal being to cover as much distance as possible and the longest distance covered during the 2-MWT was retained.

Magnetic resonance imaging (MRI) was performed on 9 patients with FSHD by using a 1.5-T unit (Magnetom Avento, Siemens, Erlangen, Germany). Transverse T1-, T2-weighted, and inversion 
recovery images were obtained on both thighs. No contrast media were administered.

\section{Muscle biopsies}

Samples from the quadriceps muscle of the "reference legs" were obtained by needle biopsy after local lidocaïne anesthesia at mid-thigh level, in the vastus lateralis, using the Bergström technique $[43,44]$. Each biopsy (approximatively $300 \mathrm{mg}$ ) was divided in three portions (see supplementary data): one part $(100 \mathrm{mg})$ to evaluate the respiratory parameters and mitochondrial adenosine triphosphate (ATP) synthesis; another part (40 mg) to evaluate tissue organization by hematoxylin/eosin staining of cross sections and to investigate mitochondria morphology by electron microcopy; the last part was immediately frozen in isopentane cooled to the freezing point with liquid nitrogen and stored at $-80{ }^{\circ} \mathrm{C}$, for analysis of oxidative stress markers. In 12/15 patients weakly affected by FSHD (BrookeVignos functional scale), analysis of the histological tissue organization and MRI showed no fibrosis. However, in the 3 more affected patients, muscle biopsies showed histological signs of severe end-stage feature of dystrophic process, and were too affected to allow any analysis, in agreement with no observable vastus lateralis muscle structure in MRI images (data not shown).

\section{Blood and urine samples}

Concomitantly with the muscle biopsy, venous blood samples were collected to determine the serum levels of oxidative stress and inflammatory markers. In two patients with FSHD, (different from the three patients where biopsy samples were too affected to allow any analysis), it was not possible to obtain enough venous blood samples to determine all the parameters. Each parameter was routinely determined at the CHU Clinical Laboratories of the University of Liège, Belgium. Normal reference values in a population of 100 healthy, 18- to 60-year-old individuals have recently been published [45-47]. Samples were collected in ethylenediaminetetraacetic acid (EDTA), sodium-heparin as anticoagulant, or clot-activating gel according to the investigated parameter and immediately centrifuged; plasmas were frozen in dry ice and kept at $-80{ }^{\circ} \mathrm{C}$ until analysis (see supplemental data). Urine samples were collected to determine the level of an oxidative damage DNA adduct and kept at $-80{ }^{\circ} \mathrm{C}$ until analysis (see supplementary data).

\section{Statistical analysis}

Quantitative parameters are presented as means \pm standard deviation (SD) or standard error of the mean (SEM). Their distribution was compared with the Student $t$ test (a transformation for a normalized distribution was applied when necessary) or the Mann-Whitney test. The distribution of inflammatory parameters was compared with the two-sided Fisher's exact test. Correlations were fitted with the Spearman rank sum test because linearity could not be assumed for all correlations. For all analyses, $\alpha$ was set at $5 \%$. Statistical analyses were performed with the Stata v6.0 software (Stata Corporation, College Station, TX).

\section{Results}

\section{Functional limitations in patients with FSHD}

Spirometric values did not show any significant respiratory difference between patients with FSHD and controls, except for the maximal expiratory pressure $\left(P_{\text {Emax }}\right)$, which was significantly lower in patients (Table 1 ). They also had lower maximal voluntary contraction (MVC) and endurance limit time $\left(T_{\mathrm{Lim}}\right)$ for both quadriceps and deltoid than controls (Table 1). However, the endurance limit time decrease in quadriceps $\left(T_{\text {Limo }}\right)$ was not significant $(P=0.10)$. Moreover, in patients there was a significant positive relationship between the $T_{\text {Lim }}$ and the MVC values (rho $=0.65 ; P=0.01$ ) in quadriceps, but not in deltoid. Exercise tolerance, assessed with the 2-MWT, was significantly lower in patients with FSHD than in controls (Table 1).

\section{Oxidative stress in FSHD muscles}

Lipofuscin inclusions, a marker of cumulative oxidative stress [48-51], were significantly more abundant in FSHD than in control quadriceps biopsies $(P<0.001)$ (Fig. $1 \mathrm{~A})$. They were mostly located in the subsarcolemmal area, a region rich in mitochondria and an important source of reactive oxygen species (ROS) (Fig. 1B, inset). The level of 4-hydroxy-2-nonenal (HNE) and the concentration of thiobarbituric acid-reactive substances (TBARs), two major end products of lipid peroxidation, as well as the level of protein carbonylation, which is the most widely used marker of oxidative stress [52,53], were all significantly higher in FSHD than in control muscles $(P<0.001$ for the three) (Fig. $2 \mathrm{~A}, \mathrm{~B}$, and $\mathrm{C})$.

While the decrease of MnSOD in FSHD muscles was not significant $(P=0.22)$ (data not shown), catalase, copper-zincdependent superoxide dismutase (Cu-Zn SOD), and glutathione reductase (GR) (all intracellular antioxidant enzymes) were significantly more elevated in FSHD than control muscles $(P=0.05$, $P=0.0005$, and $P=0.0006$, respectively) (Fig. 2D).

Together, these results demonstrate that an increase in oxidative stress in FSHD skeletal muscle biopsies is associated with altered expression of antioxidant enzymes.

Table 1

Spirometric and musculoskeletal functional data in 15 patients with FSHD and 9 controls.

\begin{tabular}{|c|c|c|c|}
\hline & FSHD patients $(n=15)$ Mean (SD) & Controls $(n=9)$ Mean (SD) & $P$ value \\
\hline \multicolumn{4}{|l|}{ Respiratory function (\% predicted) } \\
\hline Vital capacity & $101(16)$ & $108(14)$ & 0.17 \\
\hline Total lung capacity & $99(12)$ & $105(11)$ & 0.33 \\
\hline Maximal inspiratory pressure & $102(26)$ & $109(32)$ & 0.47 \\
\hline Maximal expiratory pressure & $86(34)$ & $141(41)$ & 0.006 \\
\hline \multicolumn{4}{|l|}{ Peripheral muscle function } \\
\hline Maximal contraction $\left(\mathrm{MVC}_{\mathrm{Q}}\right)$ : best leg $(\mathrm{kg})$ & $15.7(8.9)$ & $29.0(9.2)$ & 0.004 \\
\hline Endurance ( $\left.T_{\text {LimQ }}\right)$ : best legs (seconds) & $384(353)$ & $603(357)$ & 0.10 \\
\hline Maximal contraction $\left(\mathrm{MVC}_{\mathrm{D}}\right)$ : dominant $\operatorname{arm}(\mathrm{kg})$ & $6.7(2.6)$ & $11.7(3.1)$ & 0.009 \\
\hline Endurance $\left(T_{\text {LimD }}\right)$ : dominant arm (seconds) & $55.8(21.1)$ & $82.2(35.2)$ & 0.02 \\
\hline 2-minute walking test (meters) & $187(49)$ & $255(36)$ & 0.002 \\
\hline
\end{tabular}

Data are mean \pm standard deviation $(\mathrm{SD})$. 


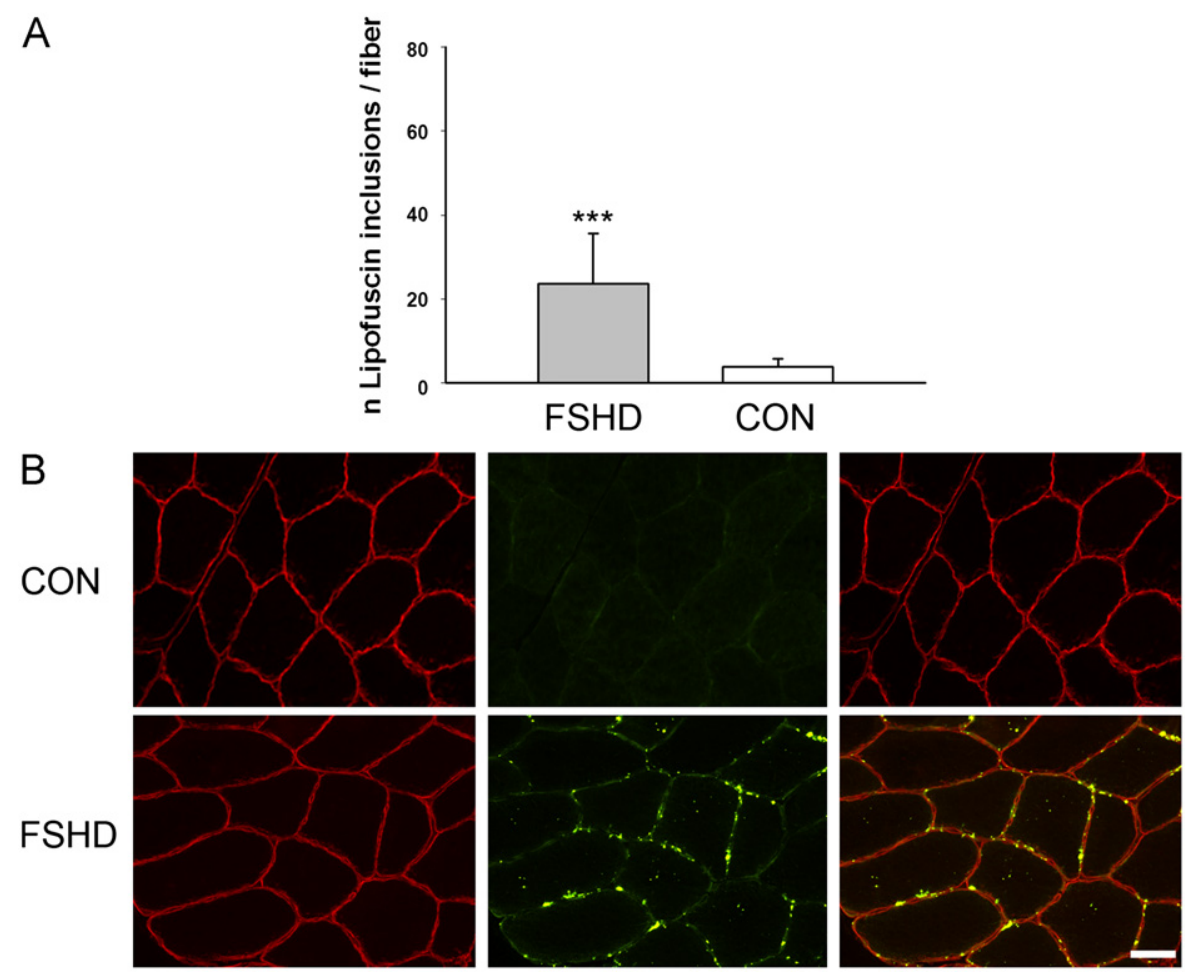

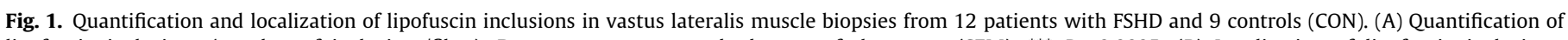

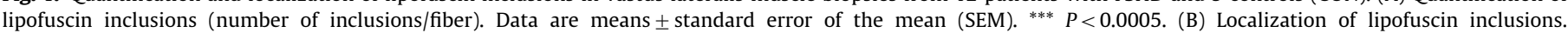

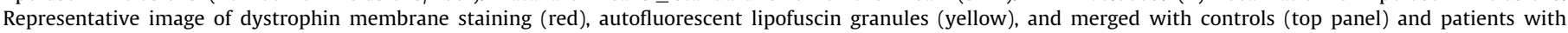
FSHD (bottom panel). Bar scale: $50 \mu \mathrm{m}$.
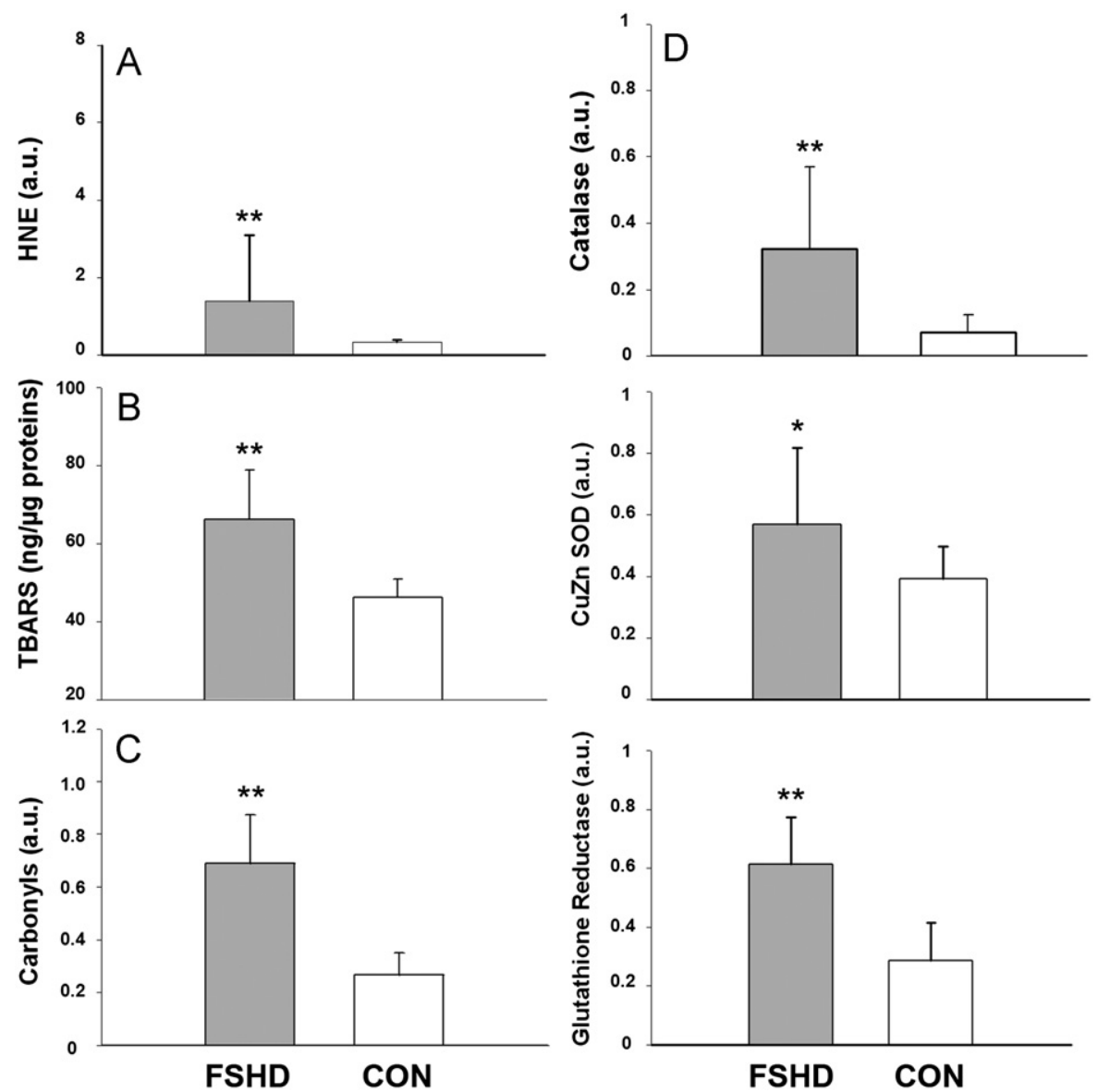

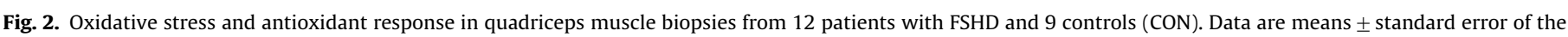

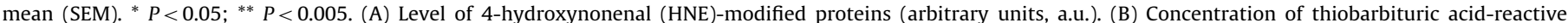

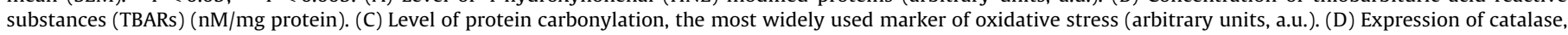
copper-zinc-dependent SOD (Cu-Zn SOD), and glutathione reductase (GR) (arbitrary units, a.u.). 
Alteration of mitochondrial ultrastructure in the FSHD skeletal muscles

The quadriceps ultrastructure and particularly the mitochondrial organization were analyzed in longitudinal sections. In control muscles (Fig. 3A) intermyofibrillar mitochondria (arrowhead) were mainly organized in pairs at the I-band, as described [54]. In FSHD muscle fibers (Fig. 3B, C, and D), a similar mitochondrial organization was observed; however, in some areas the myofibril and mitochondria ultrastructure was markedly altered, e.g., large mitochondria pools in the intermyofibrillar (arrowhead) and subsarcolemmal (arrow) compartments (Fig. 3B). In addition, within individual muscle fibers, regions containing normal myofibrils alternated with areas of pronounced myofibrillar disorganization often associated with mitochondria accumulations (Fig. 3C). This abnormal proliferation of intermyofibrillar mitochondria was associated with accumulation of "granulofilamentous material" (Fig. 3C, arrow). At higher magnification, mitochondria with some badly formed cristae and apparent swelling (Fig. 3D, arrow) or separation of the inner and outer membranes were observed in these disorganized regions.

\section{Mitochondrial dysfunction in FSHD skeletal muscles}

Mitochondrial respiration was studied in situ in saponin-skinned quadriceps fibers as described [55,56] (Table 2). While the maximal ADP-stimulated respiration (state $3 ; V_{\max }$ ) with complex I (pyruvate+malate) and complex II (succinate/rotenone) substrates was comparable in FSHD and control muscle fibers, a significant decrease in cytochrome $c$ oxidase (COX) activity (the last respiratory chain enzyme), determined with complex IV activators $\left(N, N, N^{\prime}, N^{\prime}\right.$-tetramethyl-p-phenylenediamine (TMPD) and ascorbate), was observed. However, the reduction of COX activity did not affect the total mitochondrial respiration rates evaluated with different substrates that assess electron transport in the respiratory chain. The Respiratory Control Index (RCI) was comparable in FSHD and control skinned fibers as well as the level of citrate synthase (an enzymatic marker of the mitochondrial matrix). The altered complex IV activity did not result from decreased cytochrome $c$ content because similar levels were found in FSHD and control muscles (Table 2).

The ATP synthesis capacity of the OXPHOS pathway was also measured directly in saponin-skinned fibers suspended in mitochondrial medium and supplied with respiratory substrates and ADP [57], as in the oxygraphic experiments. A decrease in ATP synthesis and in the ATP/O values (ratio between ATP synthesis and oxygen consumption) was observed in FSHD fibers, using pyruvate + malate or succinate as substrates and TMPD/ascorbate as activators. However, ATP synthase (ATPase) concentration, assessed by immunodetection on Western blots with antibodies against its alpha or beta subunits, was comparable in FSHD and control samples (Table 2). A negative correlation was only found between the mitochondrial ATP synthesis and the level of protein carbonylation (rho $=-0.65 ; P=0.03$ ).

In conclusion both ultrastructural morphological changes and functional assays point to deregulations of the mitochondrial respiratory machinery in FSHD muscles.
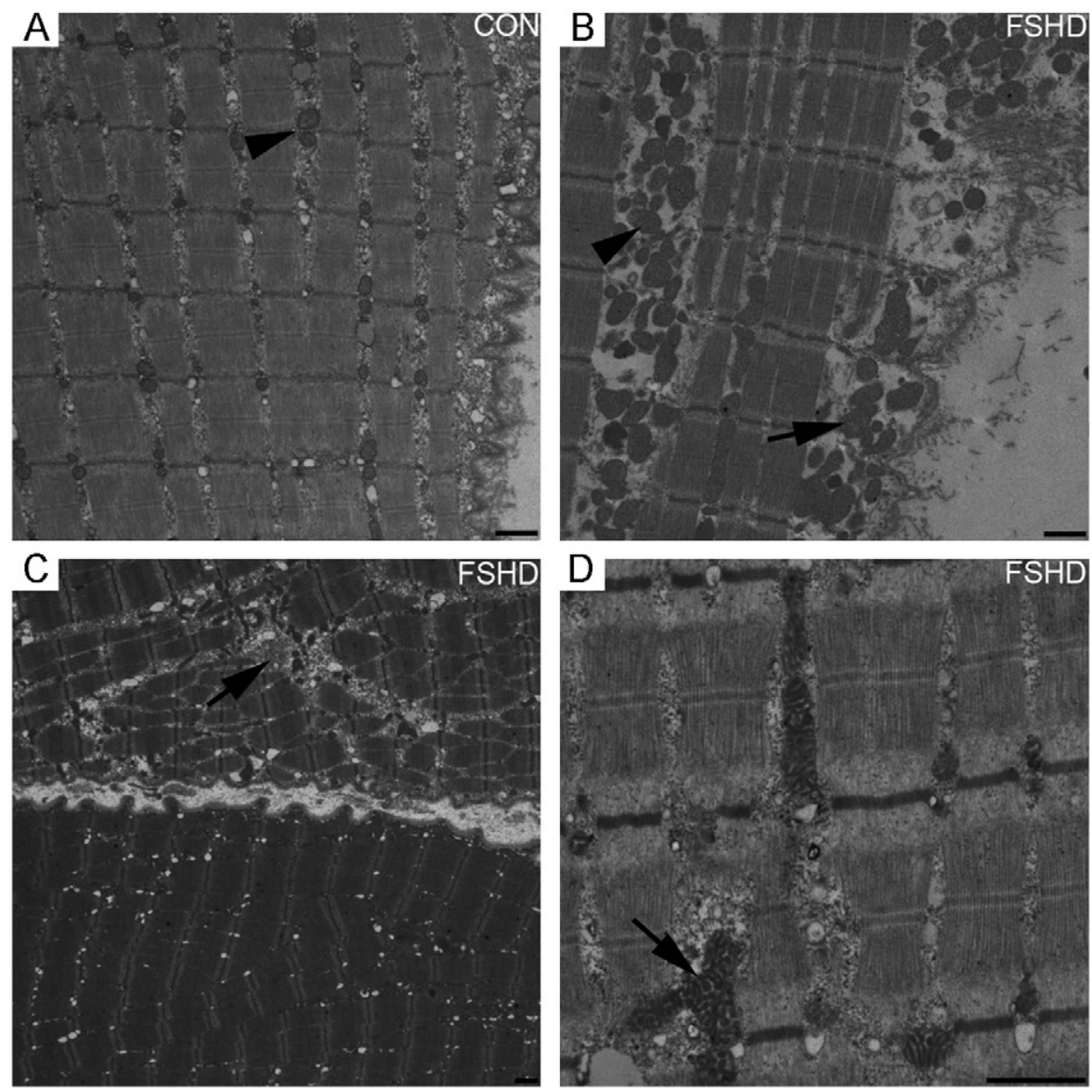

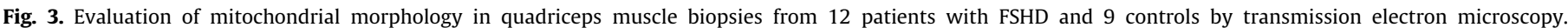
Longitudinal sections from control (A) and FSHD (B, C, and D) quadriceps muscle. Bar scale: $1 \mu \mathrm{M}$. 
Table 2

Assessment of mitochondrial function on skinned fibers of 12 FSHD and 9 control muscles.

\begin{tabular}{|c|c|c|c|}
\hline & FSHD patients $(n=12)$ Mean (SD) & Controls $(n=9)$ Mean (SD) & $P$ value \\
\hline \multicolumn{4}{|c|}{ Skinned fibers: oxygraphy ( $\mathrm{nmol} \mathrm{O}_{2} \min ^{-1} \mathrm{mg}^{-1} \mathrm{dw}$ ) } \\
\hline$V_{\mathrm{O}}$ (pyruvate + malate) & $0.002(0.0009)$ & $0.002(0.0005)$ & 0.97 \\
\hline$V_{\max }($ pyruvate + malate $)$ & $0.005(0.002)$ & $0.006(0.001)$ & 0.62 \\
\hline$V_{\max }$ (succinate/rotenone) & $0.005(0.001)$ & $0.005(0.001)$ & 0.83 \\
\hline$V_{\max }(\mathrm{TMPD}+$ ascorbate) & $0.006(0.001)$ & $0.12(0.33)$ & 0.003 \\
\hline $\mathrm{RCI}$ & $2.50(0.20)$ & $2.60(0.20)$ & 0.17 \\
\hline Citrate synthase activity ( $\mu \mathrm{mol} \mathrm{min}^{-1} \mathrm{mg}$ protein) & $0.99(0.2)$ & $0.99(0.16)$ & 0.99 \\
\hline Cytochrome $c$ (a.u.) & $0.97(0.019)$ & $0.979(0.019)$ & 0.52 \\
\hline \multicolumn{4}{|c|}{ Skinned fibers: ATP production (nmol ATP $\min ^{-1} \mathbf{m g}^{-1} \mathbf{d w}$ ) } \\
\hline ATP (pyruvate + malate) & $0.009(0.003)$ & $0.014(0.004)$ & 0.002 \\
\hline ATP/O (pyruvate + malate) & $2.52(0.16)$ & $2.68(0.11)$ & 0.002 \\
\hline ATP succinate & $0.003(0.001)$ & $0.008(0.002)$ & 0.0002 \\
\hline ATP/O succinate & $0.623(0.21)$ & $1.480(0.185)$ & 0.0001 \\
\hline ATP (TMPD+ ascorbate) & $0.003(0.0005)$ & $0.005(0.001)$ & 0.001 \\
\hline ATP/O (TMPD + ascorbate) & $0.426(0.05)$ & $0.537(0.267)$ & 0.0004 \\
\hline \multicolumn{4}{|l|}{ ATPase subunits (a.u.) } \\
\hline ATPase $\alpha$ & $0.61(0.05)$ & $0.70(0.09)$ & 0.43 \\
\hline ATPase $\beta$ & $0.72(0.12)$ & $0.70(0.09)$ & 0.80 \\
\hline
\end{tabular}

Basal $\left(V_{0}\right)$, without adenosine diphosphate (ADP) and ADP-stimulated $\left(V_{\max }\right)$ oxygen consumption rates, supported by pyruvate + malate and succinate/rotenone as substrates and TMPD/ascorbate as activators, are expressed in nmol atom oxygen/min/mg dry weight. The Respiratory Control Index $(\mathrm{RCI})$ was calculated as the $V_{\max } / V_{0}$ ratio. The ATP synthesis rate is expressed in $\mathrm{nmol}$ ATP/min/mg dry weight. The ATP/oxygen ratio (ATP/O) was calculated as the ratio between the rates of ATP synthesis and of the concomitant oxygen consumption in the presence of ADP. Citrate synthase activity is expressed in $\mu \mathrm{mol} / \mathrm{min} / \mathrm{mg}$. ATPase subunit and cytochrome $c$ expression are in arbitrary units.
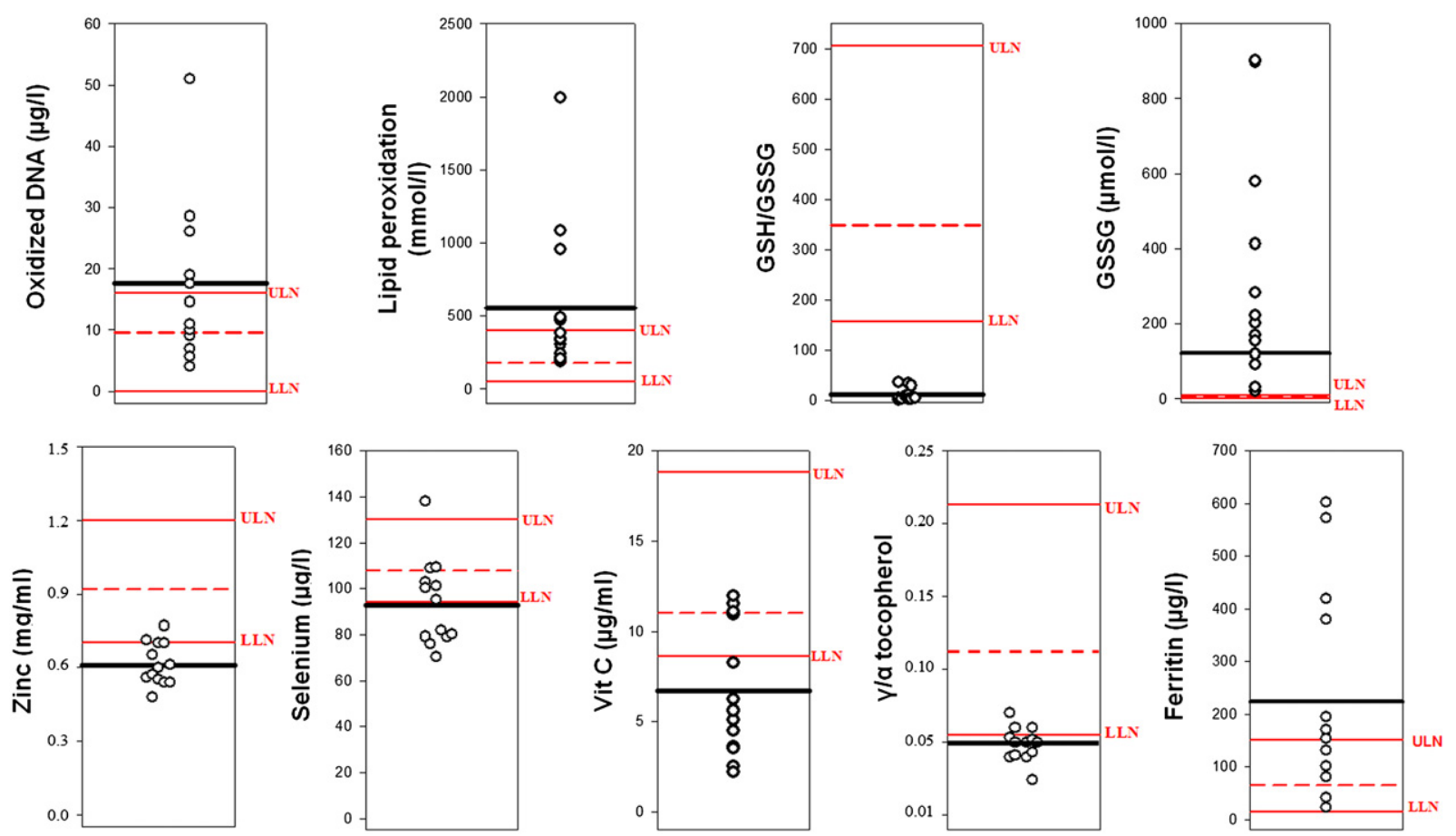

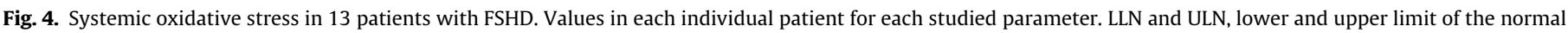
value obtained in a large normal population; red dashed line, mean value of control subjects; black solid line, mean value of FSHD patients.

\section{Systemic oxidative stress and inflammation in FSHD}

For all systemic oxidative stress markers analyzed in this study, the mean values remained within the reference norm established by the Clinical Laboratories of the University of Liege Hospital [47], in the control group, while differences were observed in the disease group (Fig. 4). Moreover, this analysis indicated that patients with FSHD had higher oxidative damage than controls. Specifically, patients had lower levels of oxidized DNA and lipid peroxidation compared to the control group
( $P=0.09$ and $P=0.002$, respectively) (Fig. 4). However, the oxidized DNA decrease in blood was not significant. The ratio between reduced (GSH) and oxidized glutathione (GSSG) was strongly decreased in all FSHD blood samples compared to the control group $(P<0.001)$ as a consequence of GSSG accumulation $(P<0.001)$, while the GSH value remained normal (Fig. 4). Although no significant differences were observed between FSHD and control samples for many antioxidative stress molecules, such as vitamin $A$, ubiquinone, $\beta$-carotene, superoxide dismutase (SOD), glutathione peroxidase (GPX), and myeloperoxydase, 
Table 3

Association of both mitochondrial dysfunction and oxidative stress and inflammation with functional parameters in patients with FSHD.

\begin{tabular}{llll}
\hline & $\boldsymbol{T}_{\text {Lime }}$ & MVC $_{\mathbf{Q}}$ & 2-MWT \\
\hline Mitochondrial ATP & rho=0.79 & rho=0.62 & - \\
$\quad$ production $n=12$ & $P=0.003$ & $P<0.05$ & \\
TNF- $\alpha$ & rho=-0.58 & rho $=-0.74$ & - \\
$n=13$ & $P=0.03$ & $P=0.003$ & \\
GSSG & rho=-0.60 & rho=-0.56 & rho $=-0.93$ \\
$n=13$ & $P=0.03$ & $P=0.04$ & $P<0.0001$ \\
\hline
\end{tabular}

Spearman's rank correlation coefficient, rho. Underline: moderate correlations between 0.56 and 0.62 .

patients could present significantly lower levels of zinc (a SOD cofactor) and selenium (a GPx cofactor involved in the elimination of lipid peroxides) as compared to the controls $(P<0.001$ and $P<0.003$, respectively) (Fig. 4). Decreased plasma levels of vitamin $C(P=0.006)$ (Fig. 4$)$ and of its ascorbate precursor (FSHD: $1.36+/-0.30$ a.u.; controls: $2.73+/-1.47$ a.u.; $P=0.04$ ) were also observed in patients with FSHD as well as a lower ratio of gamma/ alpha tocopherol and higher ferritin concentrations than in controls $(P<0.001$ and $P=0.004$, respectively) (Fig. 4). These results suggest that patients with FSHD also have a reduced systemic antioxidative response. Except for GSSG that was negatively correlated with the GSH/GSSG ratio (rho $=-0.90$, $P<0.0001$ ), no correlation was observed between any measures of injury nor between antioxidative stress molecules.

Increased expression of the proinflammatory cytokines RANTES (regulated on activation, normal T-cell expressed and secreted), TNF- $\alpha$ (tumor necrosis factor-alpha), and IFN- $\alpha 2$ (interferon alpha2 ) was found in all patients with FSHD $(P<0.001$ vs controls). MCP1 (monocyte chemotactic protein-1) and IL6 (interleukin 6) were increased in $67 \%$ of subjects with FSHD $(P=0.001$ and $P=0.01$, respectively, vs controls). IL1- $\alpha$ (interleukin 1 -alpha) was increased in $40 \%$ of them $(P=0.03)$ and IL1- $\beta$ (interleukin 1-beta) and IFN $\gamma$ (interferon gamma) in $33 \%$ of them $(P=0.03$ and $P=0.05$, respectively) (Supplemental Fig. 1s). A positive correlation was only found between TNF- $\alpha$ and GSSG levels (rho $=0.62 ; P=0.02$ ).

Association of both mitochondrial dysfunction and oxidative stress and inflammation with functional parameters in patients with FSHD

These data indicate that patients with FSHD have abnormal mitochondrial function and increased oxidative stress and inflammatory response in comparison with controls. Both systemic oxidative stress and mitochondrial dysfunction were correlated with functional muscle impairment. The correlations observed in the disease group were significant but some of them were moderate (Table 3). Mitochondrial ATP production was significantly correlated with both quadriceps endurance $\left(T_{\text {LimQ }}\right)$ and maximal voluntary contraction $\left(\mathrm{MVC}_{\mathrm{O}}\right.$ ) values $(\mathrm{rho}=0.79, P=0.003$; rho $=0.62, P=0.05$, respectively). No correlation was observed between the mitochondrial ATP production and the 2-MWT distance. The plasma concentration of oxidized glutathione was negatively correlated with the $T_{\text {LimQ, }} M_{V C} C_{Q}$ values, and the 2 -min walk distance values (rho= $-0.60, P=0.03$; rho $=-0.56, P=0.04 ;$ rho $=-0.93, \quad P<0.0001$, respectively). No correlation between the other systemic oxidative stress markers and functional muscle impairment was found. Only TNF- $\alpha$, among the proinflammatory cytokines, was negatively correlated with both $T_{\text {Lime }}$ and $\mathrm{MVC}_{\mathrm{Q}}$ values $(\mathrm{rho}=-0.58, P=0.03$; rho $=-0.74, P=0.003$; respectively). No association between the TNF- $\alpha$ and the 2-MWT distance was observed. These preliminary results need to be confirmed with larger samples.

\section{Discussion}

This study shows that, in patients with FSHD, functional muscle alterations are associated with mitochondrial dysfunction and oxidative stress imbalance, further supporting the idea that oxidative stress might play a role in FSHD pathophysiological mechanisms [14,29-31].

The biochemical evidence of mitochondrial dysfunction was provided by a decrease in COX activity without any effect on total mitochondrial respiration. The $V_{\max }$ (state 3 ) with pyruvate + malate was not significantly altered in FSHD patients, suggesting that COX may be inhibited without any effect on mitochondrial respiration up to a threshold beyond which a further decline in COX activity might exert an inhibitory effect. COX activity decline represents a focal electron transport chain deficit in a nonclinically affected tissue (vastus lateralis) and a decline in the ROS detoxification capacity of muscle cells. A modest reduction of COX activity can lead to ROS production [58] that can further reduce COX activity and decrease ATP levels due to oxidative damage to other mitochondrial components. Moreover, the significant reduction in COX activity may partially explain the impaired ability to synthesize ATP in FSHD mitochondria.

Since coupling of electron transport to ATP synthesis (indicated by the RCI ratio) did not differ between FSHD and control muscle fibers (Table 2 ), the reduced ATP/O ratio suggests that the alteration of oxidative phosphorylation (OXPHOS pathway) occurs in the PHOS part, i.e., the ATP synthesis rate. Impaired energy metabolism resulting from mitochondrial dysfunction has also been proposed to render cells more vulnerable to "cellular stressors" due to changes in the energy-dependent cell membrane potential [59]. These functional disturbances were associated with striking mitochondrial morphological changes in FSHD quadriceps, as revealed by electron microscopy. Both subsarcolemmal and intramyofibrillar mitochondria were affected, which indicated common alterations independent of the subcellular localization.

Furthermore, the data showing a negative correlation between mitochondrial ATP synthesis and protein carbonylation suggest that oxidative stress in skeletal muscle could probably be one of the major determinants of mitochondrial alterations. However, we cannot exclude that mitochondrial disruption occurs for a reason other than oxidative stress and that accumulation of protein carbonyls represents an effect of mitochondrial dysregulation.

These alterations were also associated with a significant increase of $\mathrm{Cu}-\mathrm{Zn}$ SOD, catalase, and GR concentrations. The reasons for these defects in FSHD muscle are unknown, but cannot be considered the consequence of tissue degeneration. Indeed, no prominent muscle wasting could be observed in the vastus lateralis biopsies from this group of patients with FSHD, either by histologic analysis or by MRIs (Fig. 5). However, it remains unclear whether the decline in mitochondrial respiratory function in FSHD muscle results from oxidative stress alone or is the consequence of synergistic effects of multiple factors, acting either independently or cooperatively with oxidative stress. Among several genes that have been proposed to be involved in the FSHD pathophysiology based on their up-regulation in patient-derived tissues or cell lines $[9,20-22,24]$ some are connected to oxidative stress such as the mitochondrial ADP/ATP carrier ANT1 [30]. Similarly, although the precise function of the FRG1 gene product is not known, overexpression studies in different animal models support a role in RNA processing [60,61], in actin bundling, and in the regulation of muscle and vasculature development $[11,62,63]$. The controversy in the literature about the actual expression levels of these genes in FSHD muscles reviewed in [64] might reflect the typical heterogeneity of the 

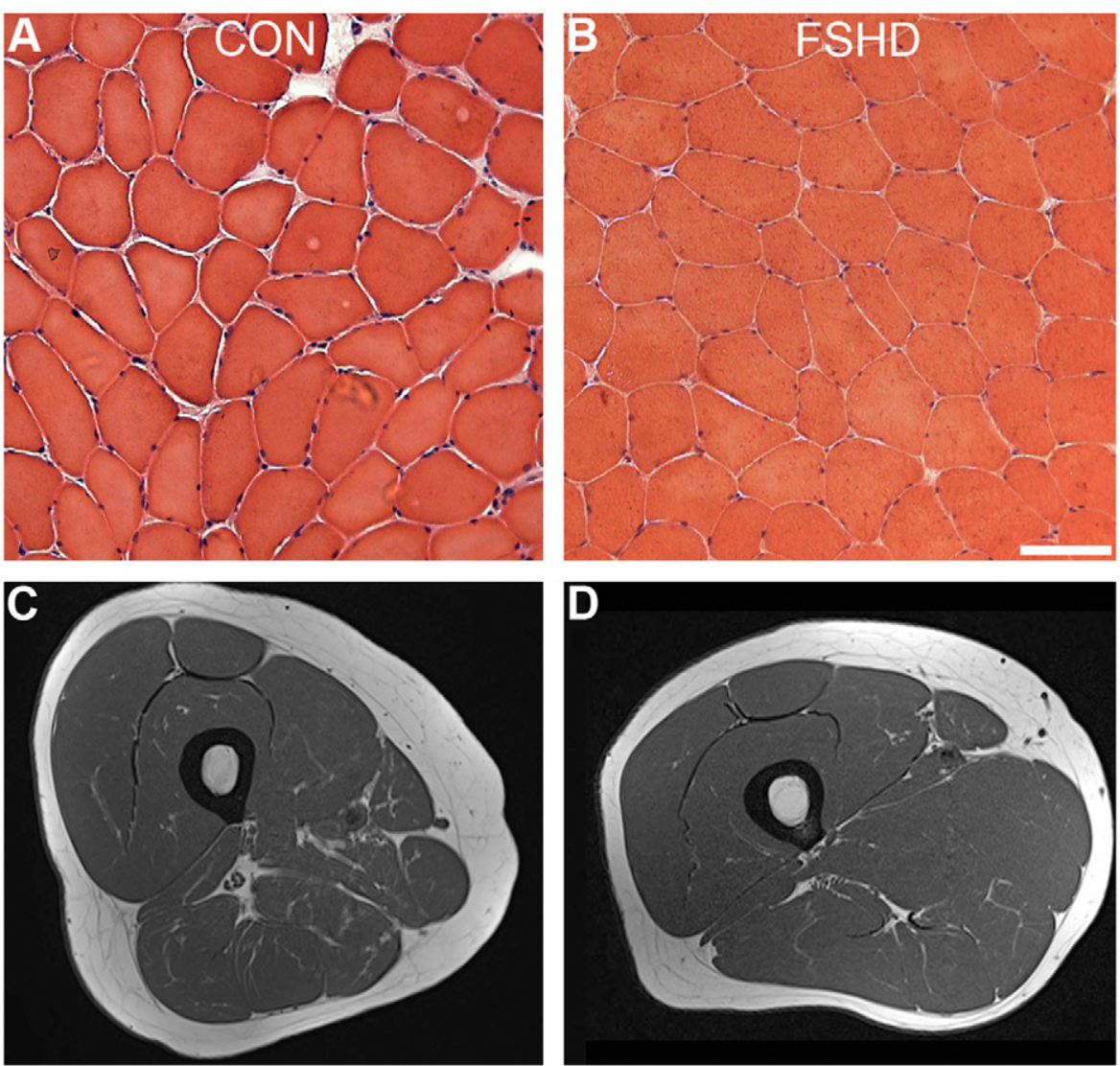

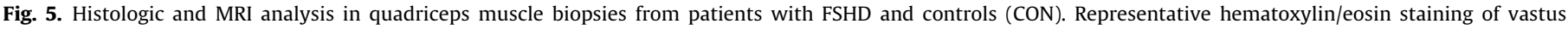

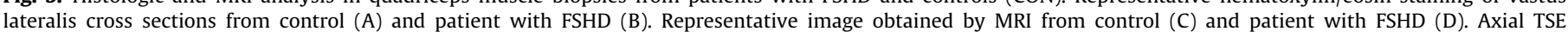
T1-weighted MR image shows normal appearance of the right thigh muscles in control and patient with FSHD.

disease phenotype and some of these genes might contribute differently to the mitochondrial dysfunction and oxidative stress among different patients or different muscles of a given patient. In a more direct mechanism, several genes involved in susceptibility to oxidative stress are affected by DUX4 expression [24,65]. Furthermore the acute cell toxicity mediated by DUX4 overexpression in mouse C2C12 myoblasts was alleviated by antioxidants such as ascorbic acid and vitamin E added to their culture medium [24].

We then show that these local alterations are associated with systemic oxidative stress and inflammation. Patients with FSHD have reduced antioxidant capacity and higher oxidative damage than age-matched controls. Some alterations were observed in most patients, such as low levels of zinc and selenium. In addition, patients frequently presented increased levels of ferritin, known to reflect the extent of oxidative stress and inflammation [66]. The significant decrease in ascorbate content suggests that patients with FSHD are subjected to free radical-induced oxidative stress that causes ascorbate consumption in plasma [67,68]. Indeed, ascorbate depletion was associated with a significant increase in lipid peroxidation and oxidized DNA.

Finally, the GSH/GSSG ratio was strongly decreased in FSHD blood samples, as a consequence of GSSG accumulation, indicating a shift to a more oxidized intracellular redox state. The GSH/GSSG ratio decrease might be related to DUX4 activation since the glutathione redox pathway was repressed on DUX4 overexpression in C2C12 cells [24]. Systemic oxidative stress was also accompanied by increased expression of proinflammatory cytokines and chemokines. The mechanisms that trigger the production of inflammatory cytokines and chemokines in FSHD are unknown, but they are likely related to GSSG accumulation [69-71].
Accordingly, TNF- $\alpha$ increase was significantly correlated with the plasma concentration of GSSG ( $r h o=0.62 ; P=0.02$ ), which is involved in the induction of proinflammatory responses, such as increased TNF- $\alpha$ release [72]. This correlation has important implications for FSHD because it supports the notion of a relationship between oxidative stress and inflammation.

The present data are in agreement with the observation that DUX4 overexpression in mouse or human myoblasts results in repression of glutathione redox pathway components and increased sensitivity to oxidative stress [24]. The correlations between systemic oxidative stress and functional muscle impairment further suggest that muscle weakness could partly result from oxidation of proteins of the contractile apparatus [73-75] and the disruption in mitochondrial energy production. In the long term, high cytokine levels might influence the exercise capacity in patients by affecting muscle function and volume. This is in agreement with our data showing a significant negative relationship between TNF- $\alpha$ and clinical functional assessments.

In conclusion, we show that markers of local and systemic oxidative stress are elevated in FSHD patients relative to controls. This leads us to propose that oxidative stress may contribute to the peripheral skeletal muscle dysfunction in FSHD. During FSHD, sustained ROS generation from inflammatory and mitochondrial origin, coupled with an inadequate antioxidant response, results in inefficient ROS scavenging in muscle and leads to long-term oxidative stress and oxidative damage of the muscle cellular components. If oxidative damage is part of the FSHD pathophysiological mechanism, then treatments that could modulate or delay the onset of the oxidative insult and mitochondrial deficiencies in muscle might be useful for maintaining FSHD muscle functions in the absence of a drug that targets the cause of FSHD. 


\section{Acknowledgments}

We are grateful to the patients of Amis FSH Europe Association Stichting FSHD (The Netherlands) and the ABMM (Belgium) for their continuous support. The authors are grateful to M.C. Granat (Department of Clinical Physiology, CHRU Montpellier, France), C. Cazevielle, and C. Sanchez (CRIC, Université Montpellier 1, France) for their assistance. We thank E. Andermarcher for critical reading of the manuscript.

\section{Appendix A. Technical appendix}

\section{Mitochondrial respiration in permeabilized skinned fibers}

High-resolution respirometry allowed a routine approach for multiple substrate-inhibitor titrations, to measure the electron transport chain (ETC) activity under physiological conditions. It is an ex vivo approach of the bioenergetic metabolism. Respiratory parameters of the total mitochondrial population were analyzed in situ using saponin-skinned muscle fibers as previously described $[55,56]$. Respiration rates were recorded in the presence of $10 \mathrm{mM}$ pyruvate and $2 \mathrm{mM}$ malate as respiratory substrates. For each sample, basal oxygen consumption without ADP (state $4 ; V_{0}$ ) was first recorded and then the ADP-stimulated maximal respiration rate (state $3 ; V_{\max }$ ) was determined in the presence of saturating concentrations of ADP (2 mM). The Respiratory Control Index (RCI) was calculated as $V_{\max } / V_{0}$ [76]. At the end of each measurement, cytochrome $c$ was added to evaluate the outer mitochondrial membrane integrity. Fiber bundles were then removed, dried for $48 \mathrm{~h}$, and weighed the next day. Replicates from the same biopsy were used to confirm the precision of the measurements. Respiration rates were expressed in nmol of $\mathrm{O}_{2} \mathrm{~min}^{-1}$ (mg dry weight $)^{-1}$.

Assessment of the different complexes of the ETC was done by successive respiration measurements after addition to the muscle fibers of $2 \mathrm{mM}$ ADP, $10 \mathrm{mM}$ pyruvate and $2 \mathrm{mM}$ malate, $20 \mu \mathrm{M}$ rotenone, $10 \mathrm{mM}$ succinate and $2 \mathrm{mM}$ malate, $6.5 \mu \mathrm{M}$ antimycin, $2 \mathrm{mM}$ ascorbate, and finally $5 \mu \mathrm{M}$ TMPD. The ADP-stimulated maximal respiration under pyruvate/malate feeding represented the maximal respiration from electron flow through complexes I, III, and IV. The ADP-stimulated maximal respiration under succinate/malate feeding, with rotenone as inhibitor of complex I, represented the maximal respiration from electron flow through complexes II, III, and IV. The ADP-stimulated maximal respiration under TMPD-ascorbate feeding, with antimycin as inhibitor of complex III, represented the maximal respiration from isolated complex IV (cytochrome oxidase complex). Fiber bundles were then removed, dried over $48 \mathrm{~h}$, and weighed the next day. Replicates from the same biopsy were used to confirm the precision of these measurements.

\section{Citrate synthase activity}

Muscle extracts were homogenized in $10 \mathrm{mmol} / \mathrm{L}$ Tris $\mathrm{HCl}$ ( $\mathrm{pH}$ 7.4). Citrate synthase activity was measured with $0.5 \mathrm{mmol} / \mathrm{L}$

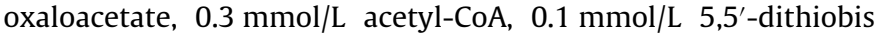
2-nitrobenzoic acid, $100 \mathrm{mmol} / \mathrm{L}$ Tris $\mathrm{HCl}(\mathrm{pH} 8.0$ ) and $0.1 \%$ ( $\mathrm{vol} / \mathrm{vol}$ ) Triton 100-X. Citrate synthase activity was monitored by recording the changes in absorbance at $412 \mathrm{~nm}$ at $37^{\circ} \mathrm{C}$ for $2.5 \mathrm{~min}$ and normalized to tissue weight.

\section{Efficiency of mitochondrial ATP production in permeabilized fibers}

Under identical conditions, the rate of mitochondrial synthesis of ATP in skinned fibers was determined using the ATP bioluminescence assay kit HS II from Roche Diagnostics $\mathrm{GmbH}$
(Mannheim, Germany) after addition of 2 mM ADP [57]. Basal respiration without ATP synthesis was measured after addition of $70 \mu \mathrm{M}$ atractyloside and $1 \mu \mathrm{M}$ oligomycin. Ten aliquots were collected from the oxygraph chamber at various time points after ADP addition, quenched in $100 \mu \mathrm{l}$ DMSO, and diluted in $5 \mathrm{ml}$ icecold distilled water. Standardization was performed with known quantities of ATP measured under the same conditions. ATP synthesis rate was expressed in nanomoles of ATP produced per minute and per milligram of fiber (dry weight). The efficiency of oxidative phosphorylation was taken as the ratio between the ATP synthesis rate and the oxygen consumption rate and was expressed as ATP/O [57].

\section{Measurements of ATPase subunits and cytochrome c in muscle} biopsies by Western blotting

Thirty micrograms of each muscle biopsy was lysed in Laemmli buffer as previously described [30]. The following primary antibodies were used: anti-ATP synthase alpha and beta (BD Biosciences) and cytochrome $c$ (Santa Cruz Biotechnology). Anti-alpha sarcomeric actin (Sigma) was used as loading control. Protein levels were quantified using the Image J Launcher Software (NIH).

\section{Transmission electron microscopy}

Freshly obtained muscle samples $(5 \mathrm{mg}$ ) were fixed in $3.5 \%$ (vol/vol) glutaraldehyde in $0.1 \mathrm{M}$ phosphate buffer, $\mathrm{pH} 7.4$, at $4{ }^{\circ} \mathrm{C}$ overnight. Samples were then prepared as previously described [77]. Electron microscopy was carried out at the Centre Régional d'Imagerie Cellulaire (CRIC) of Montpellier (France).

\section{Evaluation of oxidative stress in FSHD muscle biopsies}

Detection by fluorescence microscopy of lipofuscin, a product of the oxidation of unsaturated fatty acids, was based on its autofluorescence. Ten-micrometer quadriceps sections were mounted in Mowiol and then viewed under a fluorescence microscope with an FITC (DM510) filter. Muscle membrane staining was performed using rabbit antibody $\mathrm{H} 4$ (1:500) directed against dystrophin as previously described [78]. Immunoreactivity was detected with goat anti rabbit IgG antibodies coupled to Alexa 647 (Invitrogen 1:1000). Data were analyzed with the Histolab software (Microvision 6.1.0; license number 3105). Results were expressed as number of lipofuscin granules per fiber.

The amount of 4-hydroxy-2-nonenal-modified proteins was determined by Western blotting according to the manufacturer's recommendation (Alpha Diagnostic International; HNE11-S). Muscle thiobarbituric acid-reactive substances, used as a marker of muscle lipid peroxidation, were determined spectrophotometrically using the method described by Ohkawa et al. [79]. The final results were expressed in $\mathrm{nM} / \mathrm{mg}$ proteins. The TBAR coefficient of variation (to assess reproducibility) was less than $10 \%$. Protein oxidation was measured by evaluating the levels of carbonylated proteins by immunoblotting (S7150, Oxyblot protein oxidation detection kit; Millipore; Molsheim, France). Muscle protein carbonyl content was calculated by adding the integrated density of individual protein bands (Alpha Innotech Corporation, San Leandro, CA) obtained by Western blot analysis [80].

The antioxidant response was analyzed by Western blotting using antibodies anti-catalase 11A1 (LF-MA0010, Euromedex, Souffelweyersheim, France), which catalyzes the breakdown of hydrogen peroxide to oxygen and water, anti-glutathione reductase GR (LF-PA0056, Euromedex, Souffelweyersheim, France), an enzyme that reduces glutathione disulfide (GSSG) to the sulfhydryl form GSH, and anti-manganese superoxide dismutase MnSOD (SOD-110, Euromedex, Souffelweyersheim, France), and 
anti-copper-zinc superoxide dismutase Cu-ZnSOD (SOD-101, Euromedex, Souffelweyersheim, France) enzymes, which catalyze the reduction of superoxide anions to hydrogen peroxide. Alpha sarcomeric actin (A2172, Sigma-Aldrich, Saint-Quentin Fallavier, France) was used as loading control. For all primary antibodies, dilution was 1:1000. Secondary antibodies were coupled to horseradish peroxidase (HRP) and were sheep anti-mouse and donkey anti-rabbit IgG antibodies (respectively, NA931 and NA934, GE Healthcare Life Sciences, Velizy-Villacoublay, France) with 1:5000 dilution. Protein staining intensities were quantified using the ImageJ Launcher software (NIH). However, the small biopsy size precluded enzymatic activity assays.

\section{Evaluation of oxidative stress in FSHD blood}

\section{Antioxidants}

For vitamin $\mathrm{C}$ determination, $0.5 \mathrm{ml}$ plasma was immediately transferred in ice-cold tubes containing $0.5 \mathrm{ml}$ of $10 \%$ metaphosphoric acid and then frozen in dry ice. Analysis of vitamin $\mathrm{C}$ was performed using a spectrophotometric method and the reduction of 2,6-dichlorophenolindophenol (Perkin Elmer Lambda 40, Norwalk, USA) [81]. Plasma vitamin A, vitamin $\mathrm{E}$ ( $\alpha$ - and $\gamma$-tocopherols), and $\beta$-carotene were determined simultaneously by HPLC (Alliance Waters, USA) coupled with a diode array detector [82]. Blood levels of vitamin $E$ were normalized to those of a reference lipid (i.e., cholesterol) [83], which were determined by an enzymatic method with cholesterol oxidase. The ratio of vitamin $\mathrm{C} / \alpha$ tocopherol was used as a potential risk factor for cardiovascular disease [84]. The $\gamma / \alpha$-tocopherol ratio was determined as a sensitive index of $\alpha$-tocopherol ingestion [85]. Total GSH and GSSG were determined in whole blood using the GSH/GSSG-412 kit (Bioxytech, Oxis International Inc., Portland, WA, USA). SOD and GPx enzymatic activities in whole blood were determined with the Ransod and Ransel kits (Randox, England) and expressed as UI/g of hemoglobin. Ubiquinone analysis was performed by HPLC with a diode array detector (PDA 2996, Waters, USA) and the Co-Enzyme Q10 kit (68100) developed by Chromsystems (Germany).

\section{Trace elements}

Plasma levels of selenium, copper, and zinc were determined by inductively coupled plasma-mass spectroscopy [86].

Markers of lipid peroxidation and DNA damage. The analysis of lipid peroxides as markers of oxidative damage of lipids was performed with a commercial kit (Oxystat, Biomedica Gruppe, Austria). Briefly, the peroxide $(-\mathrm{OOH})$ concentration was determined spectrophotometrically by reaction of the biological peroxides with peroxidase and 3,30,5,50-tetramethylbenzidine as substrate. Oxidized LDL in plasma samples was determined spectrophotometrically with a competitive enzyme-linked immunosorbent assay (ELISA) kit (Immunodiagnostik, Germany). The titer of free antibodies (IgG) against antibodies bound to oxidized LDL (Ab-Ox-LDL) was assessed with a commercial enzyme immunoassay (Biomedica Gruppe, Austria) using Cu2p-oxidized LDL as antigen. 8-Hydroxy-2'deoxyguanosine (8-OHdG), an oxidative DNA damage adduct, was analyzed in fresh urine samples with the new 8-OHdG ELISA kit that uses the anti-8-OHdG monoclonal antibody (clone N45.1) developed by the Japan Institute for the Control of Aging, Nikken SEIL Co., Shizuoka, Japan. 8-OHdG concentrations were standardized to the urine dilution by expressing the data as the $8-\mathrm{OHdG} /$ urinary creatinine ratio.

Miscellaneous. Ferritin concentration was determined with the Fe kit from Roche (Roche Diagnostics) (Belgium). Myeloperoxidase, a marker of leukocyte activation, was determined with the Elisa $\mathrm{K}$ 6631 kit from Immundiagnostik, Germany.

Determination of ascorbyl free radical (AFR) content in plasma by electron spin resonance (ESR). Blood samples from patients with FSHD and healthy controls were collected in heparinized tubes which were immediately inverted five times and left at room temperature for $2 \mathrm{~h}$. Plasma samples were then obtained by centrifugation (4700g; $4{ }^{\circ} \mathrm{C} ; 10 \mathrm{~min}$ ) and immediately frozen in liquid nitrogen. Each sample was rapidly thawed, diluted in $1: 1 \mathrm{v} / \mathrm{v}$ dimethyl sulfoxide (DMSO), and placed in $50-\mu$ l calibrated glass capillary tubes (Hirschmann Lab., Germany) sealed at both ends with Critoseal. Tubes were fitted into the cylindrical cavity of a Bruker ESP 300 ESR spectrometer (Karlsruhe, Germany) operating at X-band $(9.87 \mathrm{GHz})$ with $100 \mathrm{kHz}$ modulation frequency, $10 \mathrm{~mW}$ microwave power, $0.787 \mathrm{G}$ modulation amplitude, $2.5 \times 10^{5}$ receiver gain, and $1.92 \mathrm{~ms}$ time constant. Spectral recording was initiated at room temperature $75 \mathrm{~s}$ after thawing and the relative concentration of the AFR-DMSO ESR doublet $\left(a_{\mathrm{H}}=1.83 \mathrm{G}\right)$, which resulted from the signal averaging 10 scans at $1.07 \mathrm{G} / \mathrm{s}$ sweep rate, was calculated by double integration of the simulated signal using the Winsim software [87].

\section{Blood levels of inflammatory markers}

Serum was collected by centrifugation, aliquoted, stored, and processed at the end of the study by blinded staff. Inflammatory markers were simultaneously identified using the BD cytometric bead array immunoassay (CBA) (BD Bioscience, San Jose, CA, USA). CBA is a multiplexed bead assay in which a series of spectrally discrete particles can be used to capture soluble analytes. Analytes are then quantified by flow cytometric analysis of their fluorescence-based emission. The method employs a series of different particles that are stably labeled with a discrete level of fluorescent dye whose emission wavelength is read at $\sim 650 \mathrm{~nm}$. The beads within each group are covalently coupled with antibodies that can specifically capture a particular type of molecule present in biological fluids.

\section{Appendix A. Supplementary material}

Supplementary data associated with this article can be found in the online version at http://dx.doi.org/10.1016/j.freeradbiomed. 2012.06.041.

\section{References}

[1] Olsen, D. B.; Gideon, P.; Jeppesen, T. D.; Vissing, J. Leg muscle involvement in facioscapulohumeral muscular dystrophy assessed by MRI. J. Neurol. 253:1437-1441; 2006.

[2] Pandya, S.; King, W. M.; Tawil, R. Facioscapulohumeral dystrophy. Phys. Ther 88:105-113; 2008

[3] Tawil, R.; Van Der Maarel, S. M. Facioscapulohumeral muscular dystrophy. Muscle Nerve 34:1-15; 2006.

[4] Wohlgemuth, M.; van der Kooi, E. L.; van Kesteren, R. G.; van der Maarel, S. M.; Padberg, G. W. Ventilatory support in facioscapulohumeral muscular dystrophy. Neurology 63:176-178; 2004.

[5] Laforet, P.; de Toma, C.; Eymard, B.; Becane, H. M.; Jeanpierre, M.; Fardeau, M.; Duboc, D. Cardiac involvement in genetically confirmed facioscapulohumeral muscular dystrophy. Neurology 51:1454-1456; 1998.

[6] van Deutekom, J. C.; Wijmenga, C: van Tienhoven, E. A. Gruter, A. M. Hewitt, J. E.; Padberg, G. W.; van Ommen, G. J.; Hofker, M. H.; Frants, R. R. FSHD associated DNA rearrangements are due to deletions of integral copies of a $3.2 \mathrm{~kb}$ tandemly repeated unit. Hum. Mol. Genet 2:2037-2042; 1993.

[7] Lee, J. H.; Goto, K.; Matsuda, C.; Arahata, K. Characterization of a tandemly repeated 3.3-kb KpnI unit in the facioscapulohumeral muscular dystrophy (FSHD) gene region on chromosome 4q35. Muscle Nerve 2:S6-13; 1995.

[8] Hewitt, J. E.; Lyle, R.; Clark, L. N.; Valleley, E. M.; Wright, T. J.; Wijmenga, C.; van Deutekom, J. C.; Francis, F.; Sharpe, P. T.; Hofker, M., et al. Analysis of the 
tandem repeat locus D4Z4 associated with facioscapulohumeral muscular dystrophy. Hum. Mol. Genet 3:1287-1295; 1994.

[9] Gabriels, J.; Beckers, M. C.; Ding, H.; De Vriese, A.; Plaisance, S.; van der Maarel, S. M.; Padberg, G. W.; Frants, R. R.; Hewitt, J. E.; Collen, D.; Belayew, A. Nucleotide sequence of the partially deleted D4Z4 locus in a patient with FSHD identifies a putative gene within each $3.3 \mathrm{~kb}$ element. Gene 236:25-32; 1999

[10] Arashiro, P.; Eisenberg, I.; Kho, A. T.; Cerqueira, A. M.; Canovas, M.; Silva, H. C.; Pavanello, R. C.; Verjovski-Almeida, S.; Kunkel, L. M.; Zatz, M. Transcriptional regulation differs in affected facioscapulohumeral muscular dystrophy patients compared to asymptomatic related carriers. Proc. Natl. Acad. Sci. USA 106:6220-6225; 2009.

[11] Gabellini, D.; D’Antona, G.; Moggio, M.; Prelle, A.; Zecca, C.; Adami, R.; Angeletti, B.; Ciscato, P.; Pellegrino, M. A.; Bottinelli, R.; Green, M. R.; Tupler, R. Facioscapulohumeral muscular dystrophy in mice overexpressing FRG1. Nature 439:973-977; 2006.

[12] Jiang, G.; Yang, F.; van Overveld, P. G.; Vedanarayanan, V.; van der Maarel, S.; Ehrlich, M. Testing the position-effect variegation hypothesis for facioscapulohumeral muscular dystrophy by analysis of histone modification and gene expression in subtelomeric 4q. Hum. Mol. Genet 12:2909-2921; 2003.

[13] Osborne, R. J.; Welle, S.; Venance, S. L.; Thornton, C. A.; Tawil, R. Expression profile of FSHD supports a link between retinal vasculopathy and muscular dystrophy. Neurology 68:569-577; 2007.

[14] Winokur, S. T.; Barrett, K.; Martin, J. H.; Forrester, J. R.; Simon, M.; Tawil, R.; Chung, S. A.; Masny, P. S.; Figlewicz, D. A. Facioscapulohumeral muscular dystrophy (FSHD) myoblasts demonstrate increased susceptibility to oxidative stress. Neuromuscul. Disord 13:322-333; 2003.

[15] Winokur, S. T.; Chen, Y. W.; Masny, P. S.; Martin, J. H.; Ehmsen, J. T.; Tapscott S. J.; van der Maarel, S. M.; Hayashi, Y.; Flanigan, K. M. Expression profiling of FSHD muscle supports a defect in specific stages of myogenic differentiation. Hum. Mol. Genet 12:2895-2907; 2003.

[16] Tawil, R. Facioscapulohumeral muscular dystrophy. Neurotherapeutics 5:601-606; 2008.

[17] Zeng, W.; de Greef, J. C.; Chen, Y. Y.; Chien, R.; Kong, X.; Gregson, H. C.; Winokur, S. T; Pyle, A.; Robertson, K. D.; Schmiesing, J. A.; Kimonis, V. E. Balog, J.; Frants, R. R.; Ball Jr A. R.; Lock, L. F.; Donovan, P. J.; van der Maarel, S. M.; Yokomori, K. Specific loss of histone H3 lysine 9 trimethylation and HP1gamma/cohesin binding at D4Z4 repeats is associated with facioscapulohumeral dystrophy (FSHD). PLoS Genet. :be1000559; 2009.

[18] Lunt, P. W.; Jardine, P. E.; Koch, M.; Maynard, J.; Osborn, M.; Williams, M.; Harper, P. S.; Upadhyaya, M. Phenotypic-genotypic correlation will assist genetic counseling in 4q35-facioscapulohumeral muscular dystrophy. Muscle Nerve 2:S103-109; 1995

[19] Wijmenga, C.; Deaven, L.; Frants, R. R. Dinucleotide repeat polymorphism adjacent to the ANT1 gene on 4q35. Nucleic Acids Res. 20:1161; 1992.

[20] Li, K.; Warner, C. K.; Hodge, J. A.; Minoshima, S.; Kudoh, J.; Fukuyama, R.; Maekawa, M.; Shimizu, Y.; Shimizu, N.; Wallace, D. C. A human muscle adenine nucleotide translocator gene has four exons, is located on chromosome 4, and is differentially expressed. J. Biol. Chem. 264:13998-14004; 1989.

[21] van Deutekom, J. C.; Lemmers, R. J.; Grewal, P. K.; van Geel, M.; Romberg, S.; Dauwerse, H. G.; Wright, T. J.; Padberg, G. W.; Hofker, M. H.; Hewitt, J. E.; Frants, R. R. Identification of the first gene (FRG1) from the FSHD region on human chromosome 4q35. Hum. Mol. Genet 5:581-590; 1996.

[22] Rijkers, T.; Deidda, G.; van Koningsbruggen, S.; van Geel, M.; Lemmers, R. J.; van Deutekom, J. C.; Figlewicz, D.; Hewitt, J. E.; Padberg, G. W.; Frants, R. R.; van der Maarel, S. M. FRG2, an FSHD candidate gene, is transcriptionally upregulated in differentiating primary myoblast cultures of FSHD patients. J. Med. Genet. 41:826-836; 2004.

[23] Lemmers, R. J.; van der Vliet, P. J.; Klooster, R.; Sacconi, S.; Camano, P.; Dauwerse, J. G.; Snider, L.; Straasheijm, K. R.; van Ommen, G. J.; Padberg, G. W.; Miller, D. G.; Tapscott, S. J.; Tawil, R.; Frants, R. R.; van der Maarel, S. M. A unifying genetic model for facioscapulohumeral muscular dystrophy. Science 329:1650-1653; 2010.

[24] Bosnakovski, D.; Xu, Z.; Gang, E. J.; Galindo, C. L.; Liu, M.; Simsek, T.; Garner, H. R.; Agha-Mohammadi, S.; Tassin, A.; Coppee, F.; Belayew, A.; Perlingeiro, R. R.; Kyba, M. An isogenetic myoblast expression screen identifies DUX4-mediated FSHD-associated molecular pathologies. EMBO J 27:2766-2779; 2008.

[25] Kowaljow, V.; Marcowycz, A.; Ansseau, E.; Conde, C. B.; Sauvage, S.; Matteotti, C.; Arias, C.; Corona, E. D.; Nunez, N. G.; Leo, O.; Wattiez, R.; Figlewicz, D.; Laoudj-Chenivesse, D.; Belayew, A.; Coppee, F.; Rosa, A. L. The DUX4 gene at the FSHD1A locus encodes a pro-apoptotic protein. Neuromuscul. Disord 17:611-623; 2007.

[26] Dixit, M.; Ansseau, E.; Tassin, A.; Winokur, S.; Shi, R.; Qian, H.; Sauvage, S.; Matteotti, C.; van Acker, A. M.; Leo, O.; Figlewicz, D.; Barro, M.; LaoudjChenivesse, D.; Belayew, A.; Coppee, F.; Chen, Y. W. DUX4, a candidate gene of facioscapulohumeral muscular dystrophy, encodes a transcriptional activator of PITX1. Proc. Natl. Acad. Sci. USA 104:18157-18162; 2007.

[27] Vanderplanck, C.; Ansseau, E.; Charron, S.; Stricwant, N.; Tassin, A.; Laoudj-Chenivesse, D.; Wilton, S. D.; Coppee, F.; Belayew, A. The FSHD atrophic myotube phenotype is caused by DUX4 expression. PLoS One 6:e26820; 2011

[28] Wallace, L. M.; Garwick, S. E.; Mei, W.; Belayew, A.; Coppee, F.; Ladner, K. J.; Guttridge, D.; Yang, J.; Harper, S. Q. DUX4, a candidate gene for facioscapulohumeral muscular dystrophy, causes p53-dependent myopathy in vivo. Ann. Neurol. ; 2010.

[29] Macaione, V.; Aguennouz, M.; Rodolico, C.; Mazzeo, A.; Patti, A.; Cannistraci, E.; Colantone, L.; Di Giorgio, R. M.; De Luca, G.; Vita, G. RAGE-NF-kappaB pathway activation in response to oxidative stress in facioscapulohumeral muscular dystrophy. Acta Neurol. Scand. 115:115-121; 2007.

[30] Laoudj-Chenivesse, D.; Carnac, G.; Bisbal, C.; Hugon, G.; Bouillot, S.; Desnuelle, C.; Vassetzky, Y.; Fernandez, A. Increased levels of adenine nucleotide translocator 1 protein and response to oxidative stress are early events in facioscapulohumeral muscular dystrophy muscle. J. Mol. Med. 83:216-224; 2005

[31] Celegato, B.; Capitanio, D.; Pescatori, M.; Romualdi, C.; Pacchioni, B.; Cagnin S.; Vigano, A.; Colantoni, L.; Begum, S.; Ricci, E.; Wait, R.; Lanfranchi, G.; Gelfi, C. Parallel protein and transcript profiles of FSHD patient muscles correlate to the D4Z4 arrangement and reveal a common impairment of slow to fast fibre differentiation and a general deregulation of MyoD-dependent genes. Proteomics 6:5303-5321; 2006

[32] Barro, M.; Carnac, G.; Flavier, S.; Mercier, J.; Vassetzky, Y.; Laoudj-Chenivesse D. Myoblasts from affected and non-affected FSHD muscles exhibit morphological differentiation defects. J. Cell. Mol. Med. 14:275-289; 2010.

[33] Cheli, S.; Francois, S.; Bodega, B.; Ferrari, F.; Tenedini, E.; Roncaglia, E.; Ferrari, S.; Ginelli, E.; Meneveri, R. Expression profiling of FSHD-1 and FSHD-2 cells during myogenic differentiation evidences common and distinctive gene dysregulation patterns. PLoS One 6:e20966; 2011.

[34] Vignos Jr P. J.; Spencer Jr G. E.; Archibald, K. C. Management of progressive muscular dystrophy in childhood. JAMA 184:89-96; 1963.

35] Voorrips, L. E.; Ravelli, A. C.; Dongelmans, P. C.; Deurenberg, P.; Van Staveren, W. A. A physical activity questionnaire for the elderly. Med. Sci. Sports Exerc. 23:974-979; 1991.

[36] Black, L. F.; Hyatt, R. E. Maximal respiratory pressures: normal values and relationship to age and sex. Am. Rev. Respir. Dis. 99:696-702; 1969.

[37] Koechlin, C.; Couillard, A.; Simar, D.; Cristol, J. P.; Bellet, H.; Hayot, M.; Prefaut C. Does oxidative stress alter quadriceps endurance in chronic obstructive pulmonary disease? Am. J. Respir. Crit. Care Med. 169:1022-1027; 2004.

[38] Couillard, A.; Koechlin, C.; Cristol, J. P.; Varray, A.; Prefaut, C. Evidence of local exercise-induced systemic oxidative stress in chronic obstructive pulmonary disease patients. Eur. Respir. J. 20:1123-1129; 2002

[39] Serres, I: Gautier, V.; Varray, A.; Prefaut, C. Impaired skeletal muscle endurance related to physical inactivity and altered lung function in COPD patients. Chest 113:900-905; 1998.

[40] Delample, D.; Durand, F.; Severac, A.; Belghith, M.; Mas, E.; Michel, F.; Cristol, J. P.; Hayot, M.; Prefaut, C. Implication of xanthine oxidase in muscle oxidative stress in COPD patients. Free Radic. Res. 42:807-814; 2008.

[41] Brooks, D.; Parsons, J.; Hunter, J. P.; Devlin, M.; Walker, J. The 2-minute walk test as a measure of functional improvement in persons with lower limb amputation. Arch. Phys. Med. Rehabil. 82:1478-1483; 2001.

[42] Leung, A. S.; Chan, K. K.; Sykes, K.; Chan, K. S. Reliability, validity, and responsiveness of a 2-min walk test to assess exercise capacity of COPD patients. Chest 130:119-125; 2006.

[43] Thomas, C.; Perrey, S.; Lambert, K.; Hugon, G.; Mornet, D.; Mercier, J Monocarboxylate transporters, blood lactate removal after supramaximal exercise, and fatigue indexes in humans. J. Appl. Physiol. 98:804-809; 2005.

[44] Roels, B.; Thomas, C.; Bentley, D. J.; Mercier, J.; Hayot, M.; Millet, G. Effects of intermittent hypoxic training on amino and fatty acid oxidative combustion in human permeabilized muscle fibers. J. Appl. Physiol. 102:79-86; 2007.

[45] Haleng, J.; Pincemail, J.; Defraigne, J. O.; Charlier, C.; Chapelle, J. P. [Oxidative stress]. Rev. Med. Liege 62:628-638; 2007.

[46] Pincemail, J.; Le Goff, C.; Charlier, C.; Gillion, P.; Cheramy-Bien, J. P.; Van Honacker, E.; Chapelle, J. P.; Defraigne, J. O. Evaluation biologique du stress oxydant: application en routine clinique. Nutr. Endocrinol :16-31; 2009.

[47] Pincemail, J.; Vanbelle, S.; Gaspard, U.; Collette, G.; Haleng, J.; Cheramy-Bien, J. P.; Charlier, C.; Chapelle, J. P.; Giet, D.; Albert, A.; Limet, R.; Defraigne, J. O. Effect of different contraceptive methods on the oxidative stress status in women aged 4048 years from the ELAN study in the province of Liege, Belgium. Hum. Reprod. 22:2335-2343; 2007.

[48] Tohma, H.; Hepworth, A. R.; Shavlakadze, T.; Grounds, M. D.; Arthur, P. G. Quantification of ceroid and lipofuscin in skeletal muscle. J. Histochem. Cytochem. 59:769-779; 2011.

[49] Ragusa, R. J.; Chow, C. K.; Porter, J. D. Oxidative stress as a potentia pathogenic mechanism in an animal model of Duchenne muscular dystrophy. Neuromuscul. Disord 7:379-386; 1997.

[50] Rodriguez, M. C.; Tarnopolsky, M. A. Patients with dystrophinopathy show evidence of increased oxidative stress. Free Radic Biol Med. 34:1217-1220; 2003.

[51] Nakae, Y.; Stoward, P. J.; Kashiyama, T.; Shono, M.; Akagi, A.; Matsuzaki, T.; Nonaka, I. Early onset of lipofuscin accumulation in dystrophin-deficient skeleta muscles of DMD patients and mdx mice. J. Mol. Histol. 35:489-499; 2004.

[52] Keller, R. J.; Halmes, N. C.; Hinson, J. A.; Pumford, N. R. Immunochemical detection of oxidized proteins. Chem. Res. Toxicol. 6:430-433; 1993.

[53] Stadtman, E. R.; Levine, R. L. Protein oxidation. Ann. N. Y. Acad. Sci. 899:191-208; 2000.

[54] Vendelin, M.; Beraud, N.; Guerrero, K.; Andrienko, T.; Kuznetsov, A. V. Olivares, J.; Kay, L.; Saks, V. A. Mitochondrial regular arrangement in muscle cells: a crystal-like pattern. Am. J. Physiol. Cell Physiol 288:C757-C767; 2005.

[55] Sirvent, P.; Bordenave, S.; Vermaelen, M.; Roels, B.; Vassort, G.; Mercier, J Raynaud, E.; Lacampagne, A. Simvastatin induces impairment in skeletal muscle while heart is protected. Biochem. Biophys. Res. Commun. 338:1426-1434; 2005

[56] Kuznetsov, A. V.; Veksler, V.; Gellerich, F. N.; Saks, V.; Margreiter, R.; Kunz, W. $\mathrm{S}$. Analysis of mitochondrial function in situ in permeabilized muscle fibers, tissues and cells. Nat. Protoc. 3:965-976; 2008. 
[57] Ouhabi, R.; Boue-Grabot, M.; Mazat, J. P.; Mitochondrial, A. T. P. synthesis in permeabilized cells: assessment of the ATP/O values in situ. Anal. Biochem. 263:169-175; 1998.

[58] Cardoso, S. M.; Proenca, M. T.; Santos, S.; Santana, I.; Oliveira, C. R. Cytochrome c oxidase is decreased in Alzheimer's disease platelets. Neurobiol. Aging 25:105-110; 2004.

[59] Beal, M. F. Excitotoxicity and nitric oxide in Parkinson's disease pathogenesis. Ann. Neurol. 44:S110-114; 1998.

[60] van Koningsbruggen, S.; Dirks, R. W.; Mommaas, A. M.; Onderwater, J. J.; Deidda, G.; Padberg, G. W.; Frants, R. R.; van der Maarel, S. M. FRG1P is localised in the nucleolus, Cajal bodies, and speckles. J. Med. Genet. 41:e46; 2004.

[61] van Koningsbruggen, S.; Straasheijm, K. R. Sterrenburg, E.; de Graaf, N. Dauwerse, H. G.; Frants, R. R.; van der Maarel, S. M. FRG1P-mediated aggregation of proteins involved in pre-mRNA processing. Chromosoma 116:53-64; 2007

[62] Hanel, M. L.; Wuebbles, R. D.; Jones, P. L. Muscular dystrophy candidate gene FRG1 is critical for muscle development. Dev. Dyn. 238:1502-1512; 2009.

[63] Wuebbles, R. D.; Hanel, M. L.; Jones, P. L. F. S. H. D. region gene 1 (FRG1) is crucial for angiogenesis linking FRG1 to facioscapulohumeral muscular dystrophy-associated vasculopathy. Dis. Model Mech 2:267-274; 2009.

[64] Richards, M.; Coppee, F.; Thomas, N.; Belayew, A.; Upadhyaya, M. Facioscapulohumeral muscular dystrophy (FSHD): an enigma unravelled? Hum. Genet. 131:325-340; 2012.

[65] Geng, L. N.; Yao, Z.; Snider, L.; Fong, A. P.; Cech, J. N.; Young, J. M.; van der Maarel, S. M.; Ruzzo, W. L.; Gentleman, R. C.; Tawil, R.; Tapscott, S. J. DUX4 activates germline genes, retroelements, and immune mediators: implications for facioscapulohumeral dystrophy. Dev. Cell 22:38-51; 2012.

[66] Sun, L.; Franco, O. H.; Hu, F. B.; Cai, L.; Yu, Z.; Li, H.; Ye, X.; Qi, Q.; Wang, J.; Pan, A.; Liu, Y.; Lin, X. Ferritin concentrations, metabolic syndrome, and type 2 diabetes in middle-aged and elderly chinese. J. Clin. Endocrinol. Metab. 93:4690-4696; 2008

[67] Pietri, S.; Culcasi, M.; Stella, L.; Cozzone, P. J. Ascorbyl free radical as a reliable indicator of free-radical-mediated myocardial ischemic and post-ischemic injury. A real-time continuous-flow ESR study. Eur. J. Biochem 193:845-854; 1990.

[68] Pietri, S.; Seguin, J. R.; d'Arbigny, P. D.; Culcasi, M. Ascorbyl free radical: noninvasive marker of oxidative stress in human open-heart surgery. Free Radic. Biol. Med. 16:523-528; 1994.

[69] Rovin, B. H.; Dickerson, J. A.; Tan, L. C.; Fassler, J. Modulation of IL-1-induced chemokine expression in human mesangial cells through alterations in redox status. Cytokine 9:178-186; 1997.

[70] Pena, L. R.; Hill, D. B.; McClain, C. J. Treatment with glutathione precursor decreases cytokine activity. JPEN J. Parenter. Enteral Nutr 23:1-6; 1999.

[71] Haddad, J. J.; Safieh-Garabedian, B.; Saade, N. E.; Kanaan, S. A.; Land, S. C. Chemioxyexcitation (delta pO2/ROS)-dependent release of IL-1 beta, IL-6 and TNF-alpha: evidence of cytokines as oxygen-sensitive mediators in the alveolar epithelium. Cytokine 13:138-147; 2001.

[72] Chang, L. W.; Lo, W. S.; Lin, P. Trans, trans-2,4-decadienal, a product found in cooking oil fumes, induces cell proliferation and cytokine production due to reactive oxygen species in human bronchial epithelial cells. Toxicol. Sci 87:337-343; 2005.
[73] Callahan, L. A.; She, Z. W.; Nosek, T. M. Superoxide, hydroxyl radical, and hydrogen peroxide effects on single-diaphragm fiber contractile apparatus. $J$. Appl. Physiol. 90:45-54; 2001.

[74] Spencer, T.; Posterino, G. S. Sequential effects of GSNO and $\mathrm{H}_{2} \mathrm{O}^{2}$ on the $\mathrm{Ca}^{2+}$ sensitivity of the contractile apparatus of fast- and slow-twitch skeletal muscle fibers from the rat. Am. J. Physiol. Cell Physiol 296:C1015-C1023; 2009.

[75] Edwards, J. N.; Macdonald, W. A.; van der Poel, C.; Stephenson, D. G. O2( $\left.{ }^{*-}\right)$ production at 37 degrees $C$ plays a critical role in depressing tetanic force of isolated rat and mouse skeletal muscle. Am. J. Physiol. Cell Physiol. 293:C650-C660; 2007.

[76] Saks, V. A.; Veksler, V. I.; Kuznetsov, A. V; Kay, L.; Sikk, P.; Tiivel, T.; Tranqui, L.; Olivares, J.; Winkler, K.; Wiedemann, F.; Kunz, W. S. Permeabilized cell and skinned fiber techniques in studies of mitochondrial function in vivo. Mol. Cell. Biochem. 184:81-100; 1998.

[77] Wood, D. R.; Nye, J. S.; Lamb, N. J.; Fernandez, A.; Kitzmann, M. Intracellular retention of caveolin 1 in presenilin-deficient cells. J. Biol. Chem. 280:6663-6668; 2005.

[78] Royuela, M.; Chazalette, D.; Hugon, G.; Paniagua, R.; Guerlavais, V.; Fehrentz, J. A.; Martinez, J.; Labbe, J. P.; Rivier, F.; Mornet, D. Formation of multiple complexes between beta-dystroglycan and dystrophin family products. $J$. Muscle Res. Cell Motil. 24:387-397; 2003.

[79] Ohkawa, H.; Ohishi, N.; Yagi, K. Assay for lipid peroxides in animal tissues by thiobarbituric acid reaction. Anal. Biochem. 95:351-358; 1979.

[80] Koechlin, C.; Maltais, F.; Saey, D.; Michaud, A.; LeBlanc, P.; Hayot, M.; Prefaut, C. Hypoxaemia enhances peripheral muscle oxidative stress in chronic obstructive pulmonary disease. Thorax 60:834-841; 2005.

[81] Omaye, S. T.; Turnbull, J. D.; Sauberlich, H. E. Selected methods for the determination of ascorbic acid in animal cells, tissues, and fluids. Methods Enzymol. 62:3-11; 1979.

[82] Zhao, B.; Tham, S. Y.; Lu, J.; Lai, M. H.; Lee, L. K.; Moochhala, S. M. Simultaneous determination of vitamins C, E and beta-carotene in human plasma by high-performance liquid chromatography with photodiode-array detection. J. Pharm. Pharm. Sci. 7:200-204; 2004.

[83] Thurnham, D. I.; Davies, J. A.; Crump, B. J.; Situnayake, R. D.; Davis, M. The use of different lipids to express serum tocopherol: lipid ratios for the measurement of vitamin E status. Ann. Clin. Biochem. 23(Pt 5):514-520; 1986.

[84] Gey, K. F. Vitamins E plus C and interacting conutrients required for optimal health. A critical and constructive review of epidemiology and supplementation data regarding cardiovascular disease and cancer. Biofactors 7:113-174; 1998.

[85] Baker, H.; Handelman, G. J.; Short, S.; Machlin, L. J.; Bhagavan, H. N.; Dratz, E. A.; Frank, O. Comparison of plasma alpha and gamma tocopherol levels following chronic oral administration of either all-rac-alpha-tocopheryl acetate or RRR-alpha-tocopheryl acetate in normal adult male subjects. Am. J. Clin. Nutr. 43:382-387; 1986.

[86] Sturup, S.; Hayes, R. B.; Peters, U. Development and application of a simple routine method for the determination of selenium in serum by octopole reaction system ICPMS. Anal. Bioanal. Chem 381:686-694; 2005.

[87] Duling, D. R. Simulation of multiple isotropic spin-trap EPR spectra. J. Magn. Reson. B 104:105-110; 1994. 